\title{
Deep Subcutaneous Application of Poly-L-Lactic Acid as a Filler for Facial Lipoatrophy in HIV-Infected Patients
}

\author{
$\begin{array}{llll}\text { C. Borelli C. Kunte P. Weisenseel E. Thoma-Greber } & { }^{\dagger} \quad \text { H.C. Korting B. Konz }\end{array}$ \\ Department of Dermatology and Allergy, Ludwig-Maximilian-University, Munich, Germany
}

\section{Key Words}

Highly active antiretroviral therapy · HIV infection • Lipoatrophy $\cdot$ Poly-L-lactic-acid $\cdot$ Filler

\begin{abstract}
Introduction: Facial lipoatrophy is a crucial problem of HIV-infected patients undergoing highly active antiretroviral therapy (HAART). Poly-L-lactic acid (PLA), provided as New-Fill ${ }^{\circledR} /$ Sculptra $^{\mathrm{TM}}$, is known as one possible treatment option. In 2004 PLA was approved by the FDA as Sculptra ${ }^{\mathrm{TM}}$ for the treatment of lipoatrophy of the face in HIV-infected patients. While the first trials demonstrated relevant efficacy, this was to some extent linked to unwanted effects. As the depth of injection was considered relevant in this context, the application modalities of the preparation were changed. The preparation was to be injected more deeply into subcutaneous tissue, after increased dilution. Material and Methods: To test this approach we performed a pilot study following the new recommendations in 14 patients. Results: While the efficacy turned out to be about the same, tolerability was markedly improved. The increase in facial dermal thickness was particularly obvious in those patients who had
\end{abstract}

C.B. and C.K. contributed equally to this study.

\section{KARGER}

Fax +4161306 1234 E-Mail karger@karger.ch www.karger.com
(C) 2005 S. Karger AG, Base $1660-5527 / 05 / 0186-0273 \$ 22.00 / 0$

Accessible online at: www.karger.com/spp suffered from lipoatrophy for a comparatively small period of time. Conclusion: With the new recommendations to dilute PLA powder and to inject it into the deeper subcutaneous tissue nodule formation is a minor problem. However, good treatment results can only be achieved if lipoatrophy is not too intense; treatment intervals should be about 2-3 weeks.

Copyright (C) 2005 S. Karger AG, Basel

\section{Introduction}

In the past decade considerable progress was achieved in antiretroviral therapy by the combination of reverse transcriptase inhibitors and protease inhibitors. In many patients inhibition of HIV replication could be achieved, leading to an increase in CD4 cells, termed 'immunoreconstitution', and as a result reducing the incidence of opportunistic infections followed by prolonged survival [1].

In the context of this highly active antiretroviral therapy (HAART), many patients developed the so-called lipodystrophy syndrome, in particular if based on the use of stavudine and didanosine [2-5]. The lipodystrophy syndrome is characterized by a fat distribution derangement and metabolic changes. This is a multifactorial phenomenon in which HIV infection, antiretroviral therapy,

Dr. med. Claudia Borell

Department of Dermatology and Allergy, Ludwig Maximilian University

Frauenlobstrasse 9-11

DE-80337 Munich (Germany)

Tel. +49 895160 6010, Fax +498951606312, E-Mail c.borelli@med.uni-muenchen.de 
as well as individual factors may play a role [6]. The risk of developing lipodystrophy rises with duration of treatment, patient age, degree of immunodeficiency and inflammatory states [7]. In vitro measurements have led to the hypothesis that nucleoside reverse transcriptase inhibitors (NRTI) inhibit the fatty acid proteins responsible for cellular fat uptake and intracellular fat transport. Treatment with protease inhibitors results in an extended turnover of free fatty acids with increased lipolysis and reduced clearance of VLDL triglycerides and chylomicrons. The toxic effect of NRTI on mitochondrial function is considered a major contributor to the lipodystrophy syndrome. Although adipocytes were not expected to be preferential targets of mitochondrial toxicity. A recent re-evaluation of the role of mitochondria in white adipocytes might help explain the molecular basis of HAARTassociated lipodystrophy. Adipocytes are a source of paracrine and endocrine signals that influence the biology of adipocytes and systemic metabolism. Mitochondrial disturbances induced by HAART result in abnormal perception of the bioenergetic status by adipocytes, leading to enhancement of catalytic pathways and apoptosis in peripheral adipose tissue, alterations in the differentiation of brown versus white adipocytes, and the release of hormonal signals that lead to systemic metabolic disturbances [8]. The exact pathogenesis of this type of lipoatrophy is still unclear [5].

Although there is no standardized definition of the HIV-associated lipodystrophy syndrome, it is usually classified into three different forms: lipoatrophy, central adiposity, and a combination of lipoatrophy and central adiposity. In particular structural fat is involved.

Lipoatrophy is mainly characterized by a loss of subcutaneous fat, especially in the face (nasolabial region, cheek, temples and eye sockets), the buttocks and extremities [9]. The latter leading to an accentuation of the veins of the legs. Central adiposity is characterized by an increase in the volume of the abdomen (crix belli), due to an accumulation of visceral fat, breast and nuchal fat deposition (buffalo hump). Multiple lipomas of the extremities may also develop $[10,11]$. These side effects may lead to a decrease in compliance with the treatment.

These physical changes are often accompanied by complex metabolic changes, as hypertriglyceridemia, hypercholesterolemia, increased free fatty acids, lowered high density lipoprotein (HDL), glucose tolerance disorders, diabetes and peripheral and hepatic insulin resistance. A lipodystrophy syndrome is seen in $30-50 \%$ of patients receiving HAART therapy. The metabolic changes may enhance the cardiovascular risk [12-15].
Especially the fat loss on the cheeks and temples is typical for the illness and therefore stigmatizing the HIVinfected patients which may lead to extensive psychological distress and social isolation.

In order to prevent the lipodystrophy syndrome, antiretroviral therapy should be changed as far as possible. Depending on the extent of the metabolic findings, dietary measures should be considered and smoking should be stopped. In addition, patients should do some physical exercise and a treatment with medications that lower serum lipids may be necessary $[4,5,16,17]$.

Poly- $L$-lactic acid (PLA) was recently approved in the USA as Sculptra ${ }^{\mathrm{TM}}$ for the indication of lipoatrophy in HIV-infected patients who underwent antiretroviral therapy $[18,19]$. In Europe, PLA had already been approved as New-Fill ${ }^{\circledR}$ in 1999 for soft tissue augmentation and correction of wrinkles in general [20]. PLA, a member of the $\alpha$-hydroxy acid group of compounds, is a synthetic biodegradable polymer [21]. It is made of microparticles of 40-63 $\mu \mathrm{m}$ and contains levo isomer lactic acid, polymerized to a macromolecule. New-Fill/Sculptra is hydrolyzed to water $\left(\mathrm{H}_{2} \mathrm{O}\right)$ and carbon dioxide $\left(\mathrm{CO}_{2}\right)$, which is eliminated by the lungs and kidneys. PLA increases total cutaneous thickness as shown in different studies on HIV patients who suffered from lipoatrophy during antiretroviral therapy [21,22]. The mechanism of the increase in tissue thickness is not yet known. Induction of collagen production is discussed, as well as an increase in the numbers of fibroblasts [23]. Nodule formation is the main disadvantage of this therapy. PLA is known to induce a fibrovascular and macrophage cellular infiltrate [4]. While nodules seem to occur even more often in healthy - perhaps in particular in atopic - individuals, they have also been noted in HIV-infected patients undergoing antiretroviral therapy [25]. This reduced prevalence might reflect an altered immunocompetence. Based on the experience gathered both in HIV-infected and other patients, it was tempting to speculate that comparatively superficial injections and high concentrations conforming to previous package inserts might have been the main causes of this unwanted effect $[26,27]$.

\section{Patients and Methods}

\section{Study Design}

This study was an open label, uncontrolled pilot study to evaluate the wanted and unwanted effects of PLA based on higher dilution and deeper injections in the context of facial lipoatrophy of HIV-infected patients following the recommendations of the new package insert [28]. Patients over 18 years with a facial lipoatrophy 
undergoing HAART were enrolled $(\mathrm{n}=14)$. All patients gave written informed consent to participate in the study. Before the first treatment, the thickness of fat tissue in the right upper and lower buccal region of all patients was measured by 10-MHz sonography. The dermal thickness of the right upper and lower buccal region was assessed before each treatment and after a follow-up period of 6 months. Pictures were taken before every injection, and after the follow-up period.

\section{Preparation of PLA for Injection}

Before injection, $150 \mathrm{mg}$ dry sterile PLA powder taken from 1 vial of New-Fill (Aventis Pharma Deutschland, Bad Soden, Germany) was dissolved by addition of 4-5 $\mathrm{ml}$ of water for injection (Braun, Melsungen, Germany) and $1 \mathrm{ml}$ local anesthetic (lidocaine; Prilocain ${ }^{\circledR}$ ) using an 18-gauge needle (BD Microlance ${ }^{\mathrm{TM}} 3$, BectonDickinson, Heidelberg, Germany) following the manufacturer's current recommendations, as specified in the package insert [28]. The water for injections was added slowly and without inducing pressure. For $2 \mathrm{~h}$ the New-Fill preparation was not shaken. Thereafter, the preparation was shaken using a vortexer (Mini Vortexer, Fisher Scientific, Springfield, N.J., USA, speed 10) until there were no more aggregates in the vial or later in the syringe. The local anesthetic was added immediately prior to injection.

\section{Injection Technique}

The patients were inspected first in a sitting and then in a lying position. This approach was chosen as the lesions look different according to position. It was considered helpful to begin with the injections in the cheek region, because other areas of the face can lift up through treatment of the cheek region. The next region to treat was the nasolabial fold, the third the angle of the mouth and the last the chin. At each visit, patients received several injections into the deeper subcutaneous tissue of the atrophied area of both cheeks in a row using the tunneling technique after thorough disinfection. The tunneling technique is a technique in which a cavity is formed by inserting the needle to a 30- to 40-degree angle and then lowering the needle to inject parallel to the skin. This tunnel was filled with the preparation while retracting the needle. This was performed in a criss-cross or fan-shaped manner. The dermatologic surgeons tried to inject without pressure to prevent clogging in the syringe. The syringes were only filled with $0.7 \mathrm{ml}$, not $1.0 \mathrm{ml}$, in order to gain a better handling of the syringe. Each tunnel was only filled with $0.1 \mathrm{ml}$. The injected quantity at each visit depended on the actual fat loss in the area at the given point of time. No overcorrection was intended. The injections were performed every 4-6 weeks, from 2 to 10 times according to severity. The injections were made with Luer Lok ${ }^{\mathrm{TM}} 1-\mathrm{ml}$ syringes (Becton-Dickinson, Singapore, Singapore) and 26-gauge needles (BD Microlance ${ }^{\mathrm{TM}} 3$, Becton-Dickinson). At each visit a maximum of 3-4 $\mathrm{ml}$ was injected. The injections were always performed by the same two trained dermatologic surgeons. After the injections the cheeks of the patients were thoroughly massaged to avoid nodules. The patients were instructed to massage their cheeks both from the inside and the outside in the first evening after cleansing of their hands.

\section{Clinical Evaluation Including Sonographic Measurements}

Sonographic evaluation $(10 \mathrm{MHz})$ to quantify skin thickness was performed by the same two trained dermatologists using Toshiba diagnostic ultrasound equipment (Toshiba, model SSA-340A, Tokyo, Japan) at the start and each follow-up visit including the one at 6 months after the last application. All ultrasound examinations were recorded. To find the exact region at follow-up visits, the crucial points were drawn on the patient's face. The right distal buccal area served as the index area for comparisons, both on sonographic and clinical grounds. Clinical judgement was based on photographs taken before treatment, at the end of treatment and 6 months later. Grading was as follows: deterioration -, no change =, improvement, slight + , moderate ++ , marked +++ .

\section{Statistical Evaluation}

Skin thickness data obtained before treatment, at the end of treatment and 6 months thereafter were subjected to explorative data analysis using the Wilcoxon test.

\section{Results}

Fourteen patients were enrolled and 12 patients ( 2 females and 10 males) completed the pilot study. Their ages ranged from 36 to 66 years; median age was 51.5 years. CD 4 counts at start ranged from 186 to $900 \mu \mathrm{l}^{-1}$. Patient 14 dropped out of the study suffering from a one-sided paralysis of the facial nerve occurring several days after the first treatment. The facial paralysis was considered not to be a result of the New-Fill injection, but rather of a concomitant viral infection and resolved without specific therapy after a few weeks.

The number of injections varied from patient to patient, as the patients suffered from different amounts of fat loss on their cheeks. The injections continued until the aesthetic amelioration was satisfactory in the eyes of the patients and the doctors or until it was clear that further injections would not improve the situation.

An increase in skin thickness, as measured by sonography, was observed in all patients $(p=0.001)$, as shown in table 1 in more detail. In 5 patients thickness had nearly doubled, in 5 patients it had tripled (fig. 1-3), in 1 patient it had quadrupled and quintupled in 1 patient at the end of treatment. Two patients benefited from an increase in skin thickness of about half the thickness measured initially. Within the follow-up period skin thickness tended to regress slightly again, but $\mathrm{p}$ was not significant in this case $(p=0.072)$. Skin thickness was significantly increased at the 6-month follow-up in all patients compared with skin thickness before treatment $(p=0.003)$.

Judging from the photographs, marked improvement was found in 6 patients, while no amelioration was seen in 6 patients. In 2 patients, no follow-up pictures were available. Patients with severe and/or long-standing alterations tended to respond less well. All patients who did not respond to therapy were judged as having very severe facial lipoatrophy at the beginning of the study. 


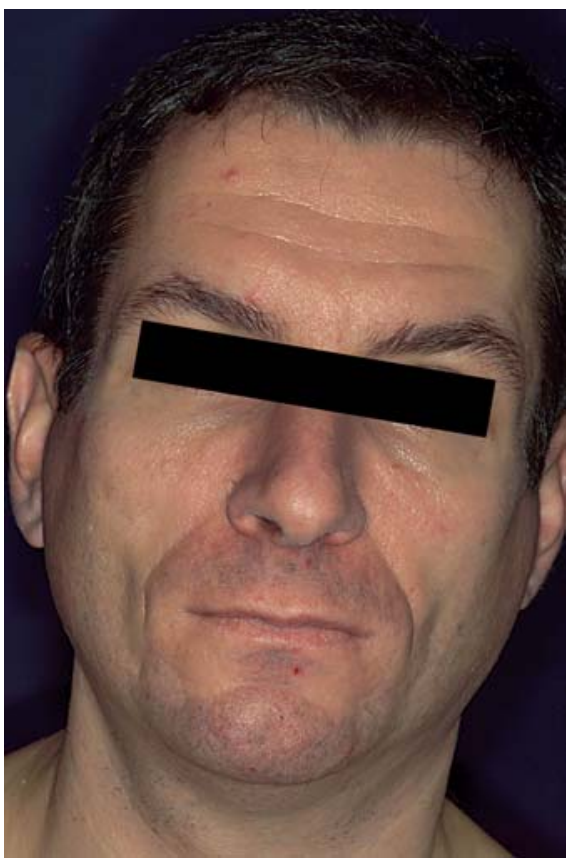

Fig. 1. Facial lipoatrophy. Male patient, clinical picture before treatment.

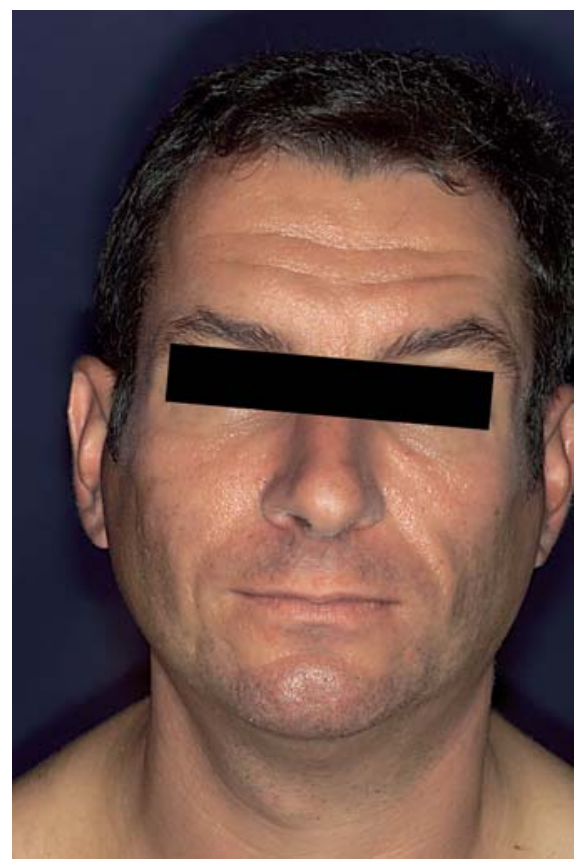

Fig. 2. Facial lipoatrophy. Male patient, clinical picture at end of treatment with PLA.

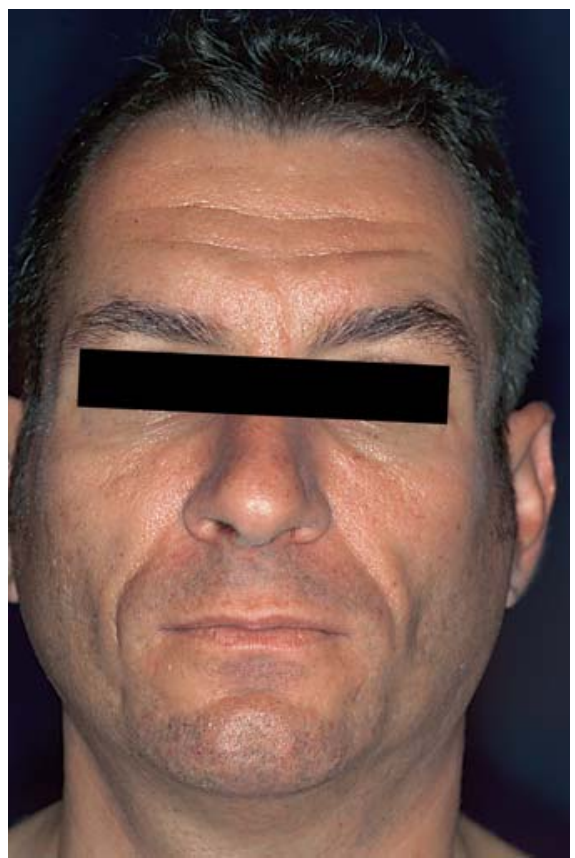

Fig. 3. Facial lipoatrophy. Male patient, clinical picture at 6-month follow-up.

Table 1. Baseline characteristics and changes with therapy

\begin{tabular}{|c|c|c|c|c|c|c|c|c|}
\hline \multirow[t]{2}{*}{ No. } & \multirow[t]{2}{*}{ Sex } & \multirow[t]{2}{*}{ Age } & \multirow[t]{2}{*}{ Applications } & \multicolumn{3}{|c|}{ Skin thickness, mm } & \multicolumn{2}{|c|}{ Improvement } \\
\hline & & & & $\begin{array}{l}\text { before } \\
\text { treatment }\end{array}$ & $\begin{array}{l}\text { after final } \\
\text { treatment }\end{array}$ & $\begin{array}{l}\text { at 6-month } \\
\text { follow-up }\end{array}$ & $\begin{array}{l}\text { after final } \\
\text { treatment }\end{array}$ & $\begin{array}{l}\text { at 6-month } \\
\text { follow-up }\end{array}$ \\
\hline 1 & $\mathrm{M}$ & 38 & 5 & 1.7 & 4.5 & 4.6 & $=$ & $=$ \\
\hline 2 & $\mathrm{M}$ & 58 & 9 & 3.3 & 6.8 & 7.1 & $=$ & $=$ \\
\hline 3 & M & 61 & 7 & 1.9 & 6.8 & 6.9 & +++ & ++ \\
\hline 4 & M & 44 & 7 & 2.9 & 5.8 & 5.5 & ++ & +++ \\
\hline 5 & M & 62 & 6 & 2.2 & 5.9 & 4.6 & $=$ & $=$ \\
\hline 6 & M & 54 & 10 & 1.7 & 6.3 & 5.9 & $=$ & $=$ \\
\hline 7 & $\mathrm{~F}$ & 43 & 5 & 3.6 & 5.3 & 5.0 & +++ & +++ \\
\hline 8 & M & 51 & 8 & 1.9 & 8.9 & 8.4 & ++ & ++ \\
\hline 9 & M & 52 & 9 & 2.3 & 4.0 & NF & $=$ & NF \\
\hline 10 & M & 37 & 7 & 2.3 & 7.1 & 6.8 & +++ & ++ \\
\hline 11 & $\mathrm{~F}$ & 34 & 4 & 2.6 & 6.1 & 5.2 & ++ & +++ \\
\hline 12 & M & 42 & 3 & 4.3 & 5.6 & $\mathrm{NF}$ & $?$ & $\mathrm{NF}$ \\
\hline 13 & $\mathrm{M}$ & 64 & 8 & 2.2 & 7.6 & 7.9 & $=$ & $=$ \\
\hline 14 & $\mathrm{M}$ & 57 & 2 & 1.6 & 3.0 & $\mathrm{NF}$ & NF & $\mathrm{NF}$ \\
\hline
\end{tabular}

Skin thickness was measured by ultrasound. Patients with excessive facial lipoatrophy $=$ no change; $+=$ slight improvement $++=$ moderate improvement $+++=$ marked improvement; $\mathrm{M}=$ male; $\mathrm{F}=$ female; $\mathrm{NF}=$ no followup; ? = no photograph to judge clinical improvement. 
The injections of New-Fill were well tolerated and no serious side-effects were seen during treatment and the follow-up period. In particular, no nodule formation was observed. One patient developed slight hyperpigmentation after excessive sun exposure. It resolved without special therapy after 1 month. One patient developed flushing at the injection site, but he was known to suffer from rosacea grade I.

\section{Discussion}

The physiologically ideal tissue filler is autologous tissue. In patients with significant lipoatrophy, however, lack of donor tissue can preclude autologous fat transfer. Additionally, transferred fat is likely to be subsequently lost in the ongoing lipoatrophy process. Purified bovine collagen dermal fillers are widely used in cosmetic procedures, but the effects usually decline after 6 months and up to $6 \%$ of patients develop localized hypersensitivity reactions. Other subcutaneous fillers such as allogenous or synthetic fillers require insertion, which can be complicated by rejection, infection, palpability and lack of natural appearance with dynamic movement. In case of central adiposity, surgery or application of growth hormones may be considered [5, 16, 25, 29].

The PLA polymer is supposed to induce collagen neogenesis, rather than a mechanical filling of defects. Tissue thickness may be enhanced by several millimeters to compensate fat loss. The possibility of developing granulomas is known especially in cosmetic applications [26, $27,29]$.

In an open label pilot study (VEGA), the efficacy and safety of PLA in HIV-infected patients with facial lipoatrophy was investigated. Fifty patients were included in the study; each of them received a total of 4 injections at intervals of 2 weeks. The follow-up period was 96 weeks. All patients had nearly complete loss of their cheek fat at the beginning of the study (thickness 0-2.1 mm). During therapy, median tissue thickness increased by $5.1 \mathrm{~mm}$ after 6 weeks, $6.4 \mathrm{~mm}$ at week 24 and $7.2 \mathrm{~mm}$ at weeks 48 and 72. At week 96 (follow-up) median tissue thickness amounted to $6.8 \mathrm{~mm}(\mathrm{p}<0.001)$. In 22 of the treated patients palpable but not visible subcutaneous nodules appeared. These nodules resolved spontaneously after 96 weeks in only 6 patients [21].

To verify these data we performed a small study with 14 patients receiving 5-9 injections of PLA at 4- to 6week intervals depending on their facial lipoatrophy. To avoid subcutaneous nodules, we chose a different recon- stitution of the PLA powder with 4-5 $\mathrm{ml}$ water for injection and $1 \mathrm{ml}$ local anesthetic [19, 28]. In the VEGA study, in contrast, the PLA powder was reconstituted with 3-4 $\mathrm{ml}$ water for injection following the former recommendations [21]. Besides the clinical assessment, we performed 10-MHz sonography and took photographs.

Tissue thickness doubled to quintupled in all our patients. The median total cutaneous thickness increased from baseline: $\pm 3.6 \mathrm{~mm}$ (range, $1.3-8.0 \mathrm{~mm}$ ) before final treatment and $\pm 3.9 \mathrm{~mm}$ (range, $1.4-7.5 \mathrm{~mm}$ ) after 6 months of follow-up. In all of our patients who completed the study we saw a significant increase in facial dermal thickness. The increase was not absolutely stable in the follow-up period, but the decrease was not significant. Aesthetic improvement could otherwise only be considered in half of the patients $(6 / 12)$ who completed the study. Even in the patients where no clinical improvement was seen, a measurable increase in tissue thickness was measured (double or triple thickness). All of these patients had a clinically pronounced lipoatrophy that was not improved after 5-10 treatment sessions.

In the VEGA study an increase of the median total cutaneous thickness was measured $\pm 6.4 \mathrm{~mm}$ at the end of therapy and $\pm 7.2 \mathrm{~mm}$ after a follow-up of 6 months [21]. Moyle et al. [22] measured an increase of the median total cutaneous thickness of 4-5 $\mathrm{mm} 8$ weeks after the final injections only in the immediate-treatment group, not in the delayed-treatment group.

Moyle et al. [22] demonstrated that an early therapy is significantly more effective on a visual analogue score than delayed treatment.

These data are consistent with our findings that early therapy with only little fat loss leads to better results than treatment in patients with extensive lipoatrophy. A probable bias in our study may be the prolonged intervals between injections that may have led to less convincing clinical results than described by Moyle et al. [22] and Valantin et al. [21]. We think that the patients who clinically did not respond to therapy are patients with severe facial fat loss; early treatment with New-Fill and shorter therapy intervals could have brought better results.

The effects of PLA have been shown to persist beyond 2 years but they are not permanent and treatment may need to be repeated [21].

While efficacy has not been a major subject of debate, safety has been considered an issue. In particular, nodule formation continues to influence the overall benefit to risk ratio [21,27]. The present pilot study demonstrated that the current changes in the application mode of PLA do not compromise efficacy; our less convincing results 
compared with the VEGA study are related to the treatment intervals, while the danger of nodule formation is virtually absent. Certainly, further large-scale trials will be needed to find out to what extent this risk is really reduced and whether efficacy is reduced as a result of the higher dilution of the PLA powder. For the time being it seems wise, in the patients' interest, to follow the modified suggestions concerning the depth of injection and dilution of the active compound.

In Germany, the price for one vial of $150 \mathrm{mg}$ PLA powder is 175 EUR. The cost-benefit ratio in our opinion is difficult to establish as the absence of a stigmatizing status of the HIV-infected patients receiving HAART cannot be quantified. Since lipoatrophy is a part of HIV and its therapy expenses should be covered by health insurance companies allowing a number of treatment sessions, as most patients are improved the first 5 injections.

\section{Conclusion}

With the new recommendations to dilute PLA powder and to inject it into the deeper subcutaneous tissue, nodule formation is a minor problem. Since it is has been shown that the effect of PLA lasts for more than 2 years, it seems to be the most effective treatment of facial lipoatrophy in HIV-infected patients receiving HAART. Good treatment results can only be achieved if lipoatrophy is not too intense; treatment intervals should be about 2-3 weeks.

\section{Acknowledgement}

The authors are grateful to Dr. Gunnel Nowald, Bad Soden, FRG, for expert advice concerning the application mode of PLA.

\section{References}

1 Palella FJ Jr, Delaney KM, Moorman AC, Loveless MO, Fuhrer J, Satten GA, Aschman DJ, Holmberg SD: Declining morbidity and mortality among patients with advanced human immunodeficiency virus infection. HIV Outpatient Study Investigators. N Engl J Med 1998;338:853-860.

2 Buffet M, Schwarzinger M, Amellal B, Gourlain K, Bui P, Prevot M, Deleuze J, Morini J, Gorin I, Calvez V, Dupin N: Mitochondrial DNA depletion in adipose tissue of HIV-infected patients with peripheral lipoatrophy. J Clin Virol 2005;33:60-64.

3 Nolan D, Mallal S: The role of nucleoside reverse transcriptase inhibitors in the fat redistribution syndrome. J HIV Ther 2004;9:3440.

4 Carr A: HIV lipodystrophy: risk factors, pathogenesis, diagnosis and management. AIDS 2003; 17(suppl 1):141-148.

5 Moyle G, Sutinen J: Managing HIV lipoatrophy. Lancet 2004;363:412-414.

6 Martinez E, Mocroft A, Garcia-Viejo MA, Perez-Cuevas JB, Blanco JL, Mallolas J, Bianchi L, Conget I, Blanch J, Phillips A, Gatell JM: Risk of lipodystrophy in HIV-1-infected patients treated with protease inhibitors: a prospective cohort study. Lancet 2001;357:592598.

7 McComsey G, Maa JF: Host factors may be more important than choice of antiretrovirals in the development of lipoatrophy. AIDS Read 2003; 13:539-542, 559 .

8 Villarroya F, Domingo P, Giralt M: Lipodystrophy associated with highly active anti-retroviral therapy for HIV infection: The adipocyte as a target of anti-retroviral-induced mitochondrial toxicity. Trends Pharmacol Sci 2005;26: 88-93.
9 James J, Carruthers A, Carruthers J: HIV-associated facial lipoatrophy. Dermatol Surg 2002;28:979-986.

10 Bornhovd E, Sakrauski AK, Bruhl H, Walli R, Plewig G, Rocken M: Multiple circumscribed subcutaneous lipomas associated with use of human immunodeficiency virus protease inhibitors? Br J Dermatol 2000; 143:1113-1114.

11 Mallon PW, Wand H, Law M, Miller J, Cooper DA, Carr A: Buffalo hump seen in HIV-associated lipodystrophy is associated with hyperinsulinemia but not dyslipidemia. J Acquir Immune Defic Syndr 2005;38:156-162.

12 Carr A: Cardiovascular risk factors in HIV-infected patients. J Acquir Immune Defic Syndr 2003;34(suppl 1):73-78.

13 Group EPL: Antiretroviral therapy, fat redistribution and hyperlipidaemia in HIV-infected children in Europe. AIDS 2004; 18:1443-1451.

14 Grinspoon S, Carr A: Cardiovascular risk and body-fat abnormalities in HIV-infected adults. N Engl J Med 2005;352:48-62.

15 Carr A, Samaras K, Burton S, Law M, Freund J, Chisholm DJ, Cooper DA: A syndrome of peripheral lipodystrophy, hyperlipidaemia and insulin resistance in patients receiving HIV protease inhibitors. AIDS 1998;12:F51-F58.

16 Cofrancesco J Jr, Brown T, Martins CR: Management options for facial lipoatrophy. AIDS Read 2004;14:639-640, 645-650.

17 Hansen BR, Haugaard SB, Iversen J, Nielsen JO, Andersen O: Impact of switching antiretroviral therapy on lipodystrophy and other metabolic complications: a review. Scand J Infect Dis 2004;36:244-253.

18 Anonymous: FDA approves lipoatrophy filler. AIDS Patient Care STDs 2004; 18:366.

19 Dermik Laboratories: New-Fill skin implant. Prescribing information, 2003.
20 Woerle B, Hanke CW, Sattler G: Poly-L-lactic acid: a temporary filler for soft tissue augmentation. J Drugs Dermatol 2004;3:385-389.

21 Valantin MA, Aubron-Olivier C, Ghosn J, Laglenne E, Pauchard M, Schoen H, Bousquet R, Katz P, Costagliola D, Katlama C: Polylactic acid implants (New-Fill) to correct facial lipoatrophy in HIV-infected patients: results of the open-label study VEGA. AIDS 2003;17: 2471-2477.

22 Moyle GJ, Lysakova L, Brown S, Sibtain N, Healy J, Priest C, Mandalia S, Barton SE: A randomized open-label study of immediate versus delayed polylactic acid injections for the cosmetic management of facial lipoatrophy in persons with HIV infection. HIV Med 2004;5:82-87.

23 Perry CM: Poly- $L$-lactic acid. Am J Clin Dermatol 2004;5:361-366; discussion 367-368.

24 Eppley BL, Reilly M: Degradation characteristics of PLLA-PGA bone fixation devices. J Craniofac Surg 1997:116-120.

25 Schurig V, Konz B, Ring J, Dorn M: Granulombildung an Test- und Behandlungsstellen durch intrakutan verabreichtes, injizierbares Kollagen. Hautarzt 1986;37:42-45.

26 Borelli C, Korting HV: Poly- $L$-lactic acid: a viewpoint by Claudia Borelli and Hans Christian Korting. Am J Clin Dermatol 2004;5:367368 .

27 Oppel T, Schaller M, Flaig M, Korting HC: Fremdkörpergranulome nach dermaler Injektion eines auf Polymilchsäure basierenden Implantates zur Behandlung von Falten. JDDG 2003;1:220-222.

28 Sculptra (injectable poly- $L$-lactic acid) Product information, Dermik Laboratories, 2004.

29 Boix V: Polylactic acid implants. A new smile for lipoatrophic faces? AIDS 2003;17:25332535 . 